\title{
SUSTENTABILIDADE, BEM-ESTAR E DIREITOS HUMANOS
}

Rubens Ricupero ${ }^{2}$

RESUMO: Neste artigo é feito um apanhado, por meio de relato pessoal do diplomata Rubens Ricupero, do estado da arte no que tange à proteçáo aos direitos individuais no Brasil, aos coletivos, como os Direitos Humanos e ao meio ambiente, especialmente após a ascensão de Jair Bolsonaro ao poder. O texto, inicialmente concebido para a na II ${ }^{a}$ Conferência Internacional de Humanidades (UFMG, UNESCO), ocorrida em dezembro de 2019, foi transformado pelo autor em artigo a ser publicado no presente dossiê, a pedido dos organizadores do número.

PALAVRAS-CHAVE: Bolsonaro. Ricupero. Sustentabilidade. Direitos Humanos no Brasil. Conferência Internacional de Humanidades.

\section{SUSTAINABILITY, WELL-BEING AND HUMAN RIGHTS}

ABSTRACT: In this essay, a summary is made, through the Brazilian diplomat Rubens Ricupero's personal report, of the state of the art with regard to the protection of individual rights in Brazil, to collectives, such as Human Rights and the environment, especially after the rise of Jair Bolsonaro to power. The text, initially conceived for the 2nd International

\footnotetext{
1 Nota dos editores: O presente artigo é resultado da participação do eminente diplomata na II $^{\mathrm{a}}$ Conferência Internacional de Humanidades, ocorrida em 09 de dezembro de 2019, em Belo Horizonte. O evento foi organizado, em parceria, pela UFMG e pela UNESCO, a agência da ONU para a Educação, a Ciência e a Cultura. A apresentação do embaixador Ricupero foi por ele transformada em texto e, agora, é publicada com ineditismo por este periódico científico, no Dossiê 28 da revista Cadernos de Campo (Unesp Araraquara), sob a organização da Profa. Dra. Luciana Santa (Ufal) e do mestrando Fernando Moreira (USP).

2 Rubens Ricupero é diplomata aposentado, ex-ministro do Meio Ambiente e da Amazônia, ex-ministro da Fazenda, foi professor da UnB e do Instituto Rio Branco, autor de diversos livros e ensaios sobre temas de história diplomática, desenvolvimento, economia, relações internacionais. Seu livro mais recente é $A$ diplomacia na construção do Brasil 1750-2016". Contato: www.rubensricupero.com.
} 
Humanities Conference (UFMG, UNESCO), held in December, 2019, was transformed by the author into an article to be published in the present dossier, at the request of the organizers.

KEYWORDS: Bolsonaro. Ricupero. Sustainability. Human Rights in Brazil. International Humanities Conference.

Ao passar os olhos pelo programa dos três dias da conferência, logo me dei conta de que seria difícil acrescentar algo de novo a temas táo variados e abrangentes. $\mathrm{O}$ melhor, pensei, seria contar um pouco de minha experiência na vida pública sobre o tratamento que os políticos profissionais costumam dar aos temas que vamos discutir, em especial os direitos humanos. A partir daí, poderemos refletir sobre o desafio fundamentalmente diferente de lidar com um governo como o atual, de ruptura e descontinuidade nessas matérias.

Tornei-me ministro pela primeira vez quando o massacre dos índios Ianomâmis na fronteira Brasil-Venezuela induziu o presidente Itamar Franco a uma decisão típica entre nós, sempre que nos defrontamos com problemas inesperados: criar um ministério. No caso, o ministério da Amazônia, dias depois incorporado ao ministério do Meio Ambiente, com o qual passou a formar uma unidade. Eu era então embaixador nos Estados Unidos, dos quais fui chamado com urgência para organizar o novo ministério (meados de 1993).

Decretado o impeachment de Collor pela Câmara dos Deputados, Itamar tomara posse num dia fatídico, 2 de outubro de 1992, data da rebelião da penitenciária do Carandiru, em São Paulo, em que foram massacrados 111 seres humanos. A partir daí parecia que se tinha inaugurado uma temporada interminável de atrocidades: Candelária (23/7/93, oito crianças e adolescentes mortos); Ianomâmis (junho/julho 93, 16 vítimas); Vigário Geral (29/8/93, 21 vítimas).

A sucessão de tantas monstruosidades com breve intervalo entre uma e outra provocou um choque na opinião pública brasileira. O fim do regime militar trouxera a ilusão de que o país havia mudado para melhor, que o meio social se tinha tornado mais compassivo, mais solidário. De repente essa crença ingênua na Nova República desmoronava sob os golpes da brutalidade contra os pobres e vulneráveis. Desde então, um sinal de como endurecemos e perdemos a esperança é que os massacres na periferia e nas prisôes viraram quase rotina sinistra à qual se reage com resignação, mais que revolta.

Pois bem, por ocasião da matança de Vigário Geral, sugeri a Itamar uma iniciativa para mobilizar a sociedade: decretar luto de três dias em homenagem às vítimas, convocar cadeia nacional de televisão e rádio para afirmar que a 
sociedade brasileira não toleraria mais tais atentados, anunciar e pôr em prática um programa de emergência de fortalecimento dos direitos humanos com participação coletiva.

A ideia básica consistia em mostrar que o problema não era só da polícia, do governo, dos políticos, mas correspondia a uma responsabilidade da sociedade como um todo. Itamar no início se inclinou a adotar a ideia, logo, porém, recuou. Explicaram-me que a causa da recusa teria sido o receio de gerar atritos com o governador Brizola, no Rio de Janeiro, em cuja gestão tinham ocorrido os últimos massacres.

Depois disso multiplicaram-se os atentados, sem que jamais qualquer governo democrático, de esquerda, direita ou centro, mostrasse compreender que problemas humanos como esses deveriam estar no topo das prioridades do Estado e da sociedade. Infelizmente, os políticos, os governantes, mesmo os de sincera identificação com o povo, ainda possuem nível de consciência incipiente da importância central de tais questóes.

Não é que sejam indiferentes ou coniventes. Até o governo passado, todos os presidentes posteriores ao regime militar empenharam-se, uns mais, outros menos, em tentar melhorar a situação dos direitos humanos, do meio ambiente, da discriminação racial. Nenhum, todavia, conferiu a essas questôes prioridade absoluta na ação governamental, refletindo nisso a tradicional atitude de moleza do Congresso, do Judiciário, das instituiçôes públicas em geral.

Em matéria de direitos humanos e aos temas correlatos, um balanço de mais de 50 anos da posição dos governos brasileiros indicaria que a evolução nessas áreas passou por três etapas distintas.

A primeira, da ditadura militar de quase 21 anos, se caracterizou pela obsessão contra a ameaça subversiva comunista ou de guerrilha, exageradamente ampliada a outras variedades de oposição ao governo. Praticou-se contra os opositores repressão sistemática e brutal, com sequestros, torturas e assassinatos que constituíam não excessos eventuais, mas politica de Estado sancionada pela aprovação explícita no mais alto nível, o do presidente, até mesmo de Geisel, conforme sabemos hoje pelas revelaçóes de comunicaçóes secretas da C.I.A.

A partir da redemocratização, muda radicalmente a natureza da questáo de direitos humanos, deixando de existir uma política repressiva de Estado dirigida sistematicamente contra opositores políticos. Voltou-se ao que sempre existiu na história brasileira, a violência institucionalizada contra os membros mais pobres e vulneráveis da sociedade, a brutalidade da vida cotidiana no Brasil profundo, a tortura praticada de modo rotineiro nas delegacias de polícia, os maus tratos contra pobres, pardos, pretos, os abusos de autoridade. 
Contra esse comportamento quase que se poderia chamar de orgânico a uma sociedade de profunda desigualdade e tradição escravagista, houve esforço sincero, mas sempre insuficiente, para melhorar as legislaçóes e as práticas. Uma a uma, as convençôes das Naçôes Unidas sobre direitos humanos rejeitadas pelos militares foram sendo adotadas e implementadas de maneira gradual e imperfeita.

O que era comum a todos os governos da redemocratização é que, sem exceção, participavam do consenso em torno dos avanços conceituais trazidos pela Constituição de 1988 em termos de direitos humanos, indígenas, meio ambiente, democracia participativa ampliada à cidadania. Nenhum se dispôs, no entanto, a contrariar interesses de peso, políticos ou econômicos, a fim de fazer avançar esses temas. Exceção notável, talvez única, constitui a decisão de Collor para impor a reserva indígena dos Ianomâmis, em Roraima, contra poderosa coalizáo de políticos, proprietários rurais e militares. O episódio que narrei sobre Itamar ilustra bem a relutância dos políticos tradicionais, mesmo os melhores, em arriscar o prestígio pessoal em questóes controvertidas de direitos humanos.

Entre 1985 e 2015, durante os primeiros 30 anos da Nova República, o consenso quase unânime da sociedade, encarnado na Constituição de 1988, serviu de base a uma progressiva ampliação das conquistas. A evolução deveu-se à ação de entidades da sociedade civil, à influência da imprensa e à ação não tanto do Legislativo, mas do Judiciário, em decisóes como as atinentes ao casamento entre homoafetivos, ao aborto ou às variadas causas ligadas à política de gênero e de orientação sexual.

É significativo que o Congresso, poder mais próximo às pressóes e orientações da opinião pública, não tenha conseguido dar forma de lei à maioria dessas modificaçóes. A dificuldade era já um sinal de que o consenso começava a ser contestado por uma evolução em curso na sociedade, em direção contrária à consagrada na Constituição. $\mathrm{O}$ primeiro dos fatores a agir nesse sentido consistiu na exacerbação do sentimento de insegurança individual como resultado do aumento assustador da criminalidade.

A repetição de massacres nas periferias, as crianças mortas por balas perdidas, a repressão policial ineficaz, a corrupção da polícia, o surgimento das facçóes de crime organizado, a propagaçáo do tráfico de drogas, tudo isso generalizou entre a população a percepção de que a legislação sobre direitos humanos favorecia aos criminosos. Criou-se a impressão de que entidades defensoras desses direitos se concentravam quase exclusivamente na explicação do crime como mero produto de condiçóes sociais estruturais. 
A ausência de políticas públicas efetivas ou o fracasso de estratégias de aperfeiçoamento no combate ao crime e da legislaçáo penitenciária deixaram campo livre aos grupos de extermínio, às milícias formadas por policiais. A frustração transformou-se em movimento político, a princípio não levado a sério, que culminou na eleição de número crescente de ex-policiais justiceiros e no surgimento da chamada "bancada da bala", fortemente contrária aos ideais de direitos humanos.

Em paralelo, outra força profunda começou a se fazer sentir, a dos amplos setores populares de orientação conservadora em costumes, moral familiar e sexual, ligados em particular às igrejas evangélicas pentecostais. A eficácia eleitoral dessas igrejas deu nascimento à "bancada da Bíblia" e à conquista de parcelas crescentes de poder político. Com isso, o cenário público brasileiro converteu-se em palco de embates de "guerra cultural" análoga em alguns aspectos à que caracteriza a política norte-americana.

Aqui, muito mais que nos Estados Unidos, registrou-se uma poderosa convergência de fatores atuando no sentido de corroer o anterior consenso embutido na Constituição de 1988: ex-policiais e militares convertidos em políticos, evangélicos pentecostais de crescente influência político-eleitoral, as milhóes de vítimas do desemprego e do retrocesso ocasionados pela crise econômica, a amargura e revolta consequentes ao impeachment de Dilma e ao colapso da hegemonia do PT.

Atuando sobre esse caldo explosivo, a operação Lava Jato produziu efeito devastador de demolição da confiança já debilitada nas instituições democráticas, no sistema de governo e nos políticos desmoralizados pelas revelaçóes quase diárias de escândalos de corrupção.

A combinação de tantas forças destrutivas, ao lado da oportunista utilização de redes sociais e do efeito do frustrado atentado contra Bolsonaro, tornou possível um resultado eleitoral sem precedentes em nossa história recente pelas suas implicaçôes de ruptura do sentido da evolução da vida política. Fruto da soma de todas essas forças, o governo Bolsonaro é intrinsicamente diferente dos precedentes, em razão dos setores sociais em que se apoia e por não participar do consenso consagrado na Constituiçáo de 1988.

Há na posição do governo uma contradição insanável. Eleito no quadro da Constituição, sem poder político suficiente para substituir a carta constitucional por outra mais afinada com suas convicções, o governo gera uma tensão permanente ao empenhar-se o tempo todo em propor alteraçóes substanciais mediante emendas (na área econômica e social, por exemplo) ou tentativas de 
testar os limites do que pode fazer por decretos ou medidas provisórias (em relação à liberação de armas, temas ambientais e outros).

É por isso que se amiudaram no primeiro ano do mandato decisóes judiciais ou do Congresso para anular, suspender ou modificar decretos ou propostas de MPs governamentais. O governo não esconde a intenção de desmantelar boa parte do que se edificou até hoje em matéria dos temas constantes desta conferência. Gostaria, se estivesse em seu poder, de apagar esses assuntos da Constituição.

Como não dispóe de poder para tanto, suprime o caráter ministerial do tratamento de alguns dos temas (direitos humanos, política de gênero, promoção de igualdade racial), anuncia a intenção de eliminar o ministério do Meio Ambiente e, frente à reação desfavorável, o entrega a um antiministro incumbido de liquidá-lo na prática. Abro aqui um parêntese para realçar o desastre que teria sido a supressão desse ministério para o próprio governo que, em menos de um ano, teve de enfrentar três magnas crises ambientais: a de Brumadinho, das queimadas na Amazônia, do derrame de óleo no Nordeste.

Em muitos aspectos, o governo Bolsonaro representa a morte da Nova República, não por um golpe que tivesse destruído a Constituição, mas pela chegada ao poder mediante eleiçóes de um grupo empenhado em liquidar o espirito, os valores e os ideais da Carta de 1988. Para todos os efeitos práticos, já estamos vivendo em uma fase histórica e política pós-Nova República, em razão da vitória eleitoral de um governo de ruptura e descontinuidade com a redemocratização.

A primeira lição a retirar dessa realidade é que não se pode lidar com um governo declaradamente comprometido com a destruição do que foi edificado antes da mesma maneira que se lidava com os anteriores. De Sarney até o governo Temer, podia-se dialogar, colaborar com vistas a aumentar a pressão em favor dos temas que fazem avançar o processo civilizatório.

Existia um terreno comum, o do consenso de 1988, uma linguagem partilhada, um método adequado, o dos conselhos deliberativos ou consultivos com representantes da sociedade civil. Nada disso é viável com um governo que se empenha em suprimir ou enfraquecer todos os conselhos, cultiva obsessão paranoica contra as Organizaçôes Náo Governamentais e nega a existência da sociedade civil ou se esforça em manipular as pessoas por meio de fake news.

O problema mudou de indole. O que temos hoje é um Executivo hostil à essência mesma dos grandes temas civilizatórios. $\mathrm{Na}$ impossibilidade de qualquer avanço neste momento, a única atitude eficaz para minimizar o dano é a da resistência, da denúncia, do apelo a instituiçóes de defesa das conquistas da Constituição, 
tais como o Judiciário, o Ministério Público, o Congresso, a imprensa, as entidades representativas da sociedade organizada.

A diferença na natureza do desafio não resulta apenas de fatos e eventos políticos e econômicos, mas de uma radical transformação no dominio das ideias, da maneira de encarar o mundo, a vida, o país. Na origem do grupo que conquistou o poder existe um movimento filosófico, doutrinário, de extrema direita, uma reorientação no campo das ideias, da filosofia, da cultura, em sentido distinto, às vezes oposto, ao que impulsionou a redemocratização e a elaboração da Constituição de 1988. Não é por acaso que essa ideologia retrocede à fase histórica anterior à redemocratização, partindo da apologia da ditadura militar.

Em outras palavras, a ascensão da extrema direita brota no Brasil de uma filosofia, de um debate de ideias, da negação dos valores predominantes até então. É um erro subestimar Olavo de Carvalho porque se trata de alguém sem credenciais acadêmicas, sem formação universitária completa, um outsider, um marginal em relação ao mundo intelectual oficial. Ele soube ocupar um vazio, fornecer uma explicação sistemática do mundo a milhares de discípulos. Ministra cursos populares, fáceis de seguir na internet, com uso habilidoso das redes sociais.

Impóe-se aqui um exame de consciência, talvez uma autocrítica, da parte dos intelectuais, das universidades públicas. Como foi possível que esse movimento filosófico, essa agitação de ideias, tivesse passado largamente despercebido? Não teria havido algum tipo de omissão, de falha no papel que a universidade pública deveria ter desempenhado em relação a seu entorno social, à sua cidade, à população não matriculada em cursos regulares, mas necessitada de orientação?

Teriam as universidades, os acadêmicos, sucumbido à tentação da "torre de marfim”, vivendo para suas carreiras, voltados somente à rotina da vida interna no campus? Existem acaso estudos, pesquisas universitárias, que nos ajudem a compreender o fenômeno da extrema direita no Brasil, sua gênese, sua base social, suas inspiraçóes intelectuais, seus meios de financiamento, seus métodos de ação? Como se explica que a melhor contribuição nesse sentido tenha vindo não da universidade, mas de uma série de matérias da revista Época no começo de 2019?

A verdade é que o movimento se gestou fora e contra a universidade pública, fora e contra as correntes principais do ensino e pesquisa acadêmicos em filosofia, ciências sociais, as humanidades do título desta Conferência, por isso mesmo vistas como inimigas a destruir, como parte principal do chamado "marxismo cultural". 
Desenvolvendo-se à margem da universidade, da vida cultural e intelectual predominantes, esse movimento apresenta características de reaçáo virulenta contra a herança das Luzes, do Iluminismo. Sua índole é antiliberal, antirracional, anticientífica, negadora da Terra redonda, da teoria da evolução, da mudança climática, movida pelo ressentimento contra as elites artísticas, intelectuais, culturais, universitárias, que se propóe a humilhar com cortes de verbas, redução de bolsas, nomeaçóes estapafúrdias de desqualificados para as mais altas funções na administração da cultura, da ciência, das artes, da educaçáo.

Não basta, contra isso, apontar a baixa qualidade intelectual dessas doutrinas. $\mathrm{O}$ desprezo não constitui estratégia para servir de contrapeso à influência de ideias, por mais equivocadas que sejam. O combate ao reacionarismo de extrema direita só será efetivo se souber se contrapor a todos seus componentes, a começar pela sua inspiração filosófica e cultural.

A superação do retrocesso não virá somente da luta no campo político, econômico e social. Da mesma forma que a extrema direita se originou e alimentou de ideias, a reação terá de provir da renovação da filosofia, da cultura, das artes. Cabe aqui um paralelo com o Centenário da Independência em 1922. O que ficou do Centenário não foi a grande Exposição Universal inaugurada em 7 de setembro, não foram os episódios da longa contestação da vitória de Artur Bernardes e de seu governo.

O que ficou do Centenário foi a Semana de Arte Moderna, a influência de Mário de Andrade, de Oswald, de Drummond, Bandeira, Villa Lobos, dos que vieram depois, arquitetos, urbanistas, músicos. Na conferência proferida na Academia Brasileira de Letras em 29 de agosto de 2019 sob o título "Brasil: um futuro pior que o passado? Reflexóes na antevéspera do Bicentenário da Independência", tratei mais extensamente do papel que coube então à revoluçáo cultural do Modernismo.

Entende-se que na época o impulso de renovação tenha partido de intelectuais avulsos como Mário de Andrade e não de uma universidade pública que só começaria a existir de fato anos, décadas mais tarde. Uma conferência como a que iniciamos hoje, reunindo reitores, professores, representantes da UNESCO, constitui o cenário apropriado para discutir o papel que terá de caber nessa obra de renovação à universidade pública, às ciências sociais, às humanidades do título do encontro.

Quais os valores, os objetivos dessa obra de renovação? Não podem deixar de ser as grandes ideias-força, os quatro ou cinco temas maiores que felizmente ocuparam o lugar das ideologias absolutistas, destrutivas, ilusórias, anti-humanistas, que fizeram da primeira metade do século 20 um campo de desolação e 
de ruínas. Impulsionadas ao longo dos últimos 75 anos pelas Naçóes Unidas, elas vêm aos poucos produzindo um conjunto de regimes jurídicos formados pelas convençôes internacionais que refletem os avanços e as conquistas humanas.

São elas: os Direitos Humanos na mais ampla acepção e abrangência, a proteção do meio ambiente, a promoção da igualdade entre mulheres e homens a de potencial de mais profunda transformação das relaçóes interpessoais - o reconhecimento e respeito da diversidade de gênero, de sexo, de cultura, a luta pela maior igualdade possivel, a erradicação da indigência, da pobreza, da doença, da ignorância. Elas se encontram hoje quantificadas em metas com prazos definidos, os 17 Objetivos de Desenvolvimento Sustentável.

Refletem o estágio mais avançado que alcançou em nossos dias a evolução da consciência moral da humanidade. Elas retomam na sua inspiração a herança que nos legou o movimento das Luzes e nos dão forças para impedir que a hora do poder das trevas se estabeleça duravelmente no Brasil e no mundo. 